\title{
Lack of evidence for a role of hydrophobins in conferring surface hydrophobicity to conidia and hyphae of Botrytis cinerea
}

\author{
Andreas Mosbach', Michaela Leroch', Kurt W Mendgen², Matthias Hahn ${ }^{1 *}$
}

\begin{abstract}
Background: Hydrophobins are small, cysteine rich, surface active proteins secreted by filamentous fungi, forming hydrophobic layers on the walls of aerial mycelia and spores. Hydrophobin mutants in a variety of fungi have been described to show 'easily wettable' phenotypes, indicating that hydrophobins play a general role in conferring surface hydrophobicity to aerial hyphae and spores.

Results: In the genome of the grey mould fungus Botrytis cinerea, genes encoding three hydrophobins and six hydrophobin-like proteins were identified. Expression analyses revealed low or no expression of these genes in conidia, while some of them showed increased or specific expression in other stages, such as sclerotia or fruiting bodies. Bhp1 belongs to the class I hydrophobins, whereas Bhp2 and Bhp3 are members of hydrophobin class II. Single, double and triple hydrophobin knock-out mutants were constructed by consecutively deleting bhp 1, bhp2 and bhp3. In addition, a mutant in the hydrophobin-like gene bh/1 was generated. The mutants were tested for germination and growth under different conditions, formation of sclerotia, ability to penetrate and infect host tissue, and for spore and mycelium surface properties. Surprisingly, none of the B. cinerea hydrophobin mutants showed obvious phenotypic defects in any of these characters. Scanning electron microscopy of the hydrophobic conidial surfaces did not reveal evidence for the presence of typical hydrophobin 'rodlet' layers.

Conclusions: These data provide evidence that in B. cinerea, hydrophobins are not involved in conferring surface hydrophobicity to conidia and aerial hyphae, and challenge their universal role in filamentous fungi. The function of some of these proteins in sclerotia and fruiting bodies remains to be investigated.
\end{abstract}

\section{Background}

Filamentous fungi produce unique proteins called hydrophobins that are secreted and cover the walls of spores and hyphae with a hydrophobic layer [1]. Structurally, hydrophobins are characterised by their small size and the presence of eight cysteine residues which are arranged in a conserved array and form four pairs of disulphide bridges. By their ability to aggregate to amphipathic membranes, they attach to the surface of the hydrophilic fungal cell wall, thereby exposing the hydrophobic layer to the outside [2]. By scanning electron microscopy, hydrophobin layers can often be recognised by the formation of rodlets of characteristic

\footnotetext{
* Correspondence: hahn@rhrk.uni-kl.de

'Department of Biology, University of Kaiserslautern, Gottlieb-Daimler-Straße, 67663 Kaiserslautern, Germany

Full list of author information is available at the end of the article
}

dimensions [3]. Hydrophobin aggregates are highly resistant against treatments that are used for solubilising proteins. Based on their amino acid sequences, hydropathy profiles and solvent solubility, two classes of hydrophobins are distinguished. While class I hydrophobin aggregates are extremely stable, and can be dissociated only in trifluoroacetic acid and formic acid, class II hydrophobin aggregates can be solubilised in hot sodium dodecyl sulphate (SDS) or $60 \%$ ethanol [2].

Hydrophobins have been shown to serve several basic functions in fungi. By covering hyphal walls with a hydrophobic surface layer, they allow hyphae to escape from aqueous substrates and to develop aerial mycelia [1]. Similarly, conidia are often covered with rodlet layers, which facilitate their dispersal by air or water droplets. Loss of the hydrophobin layers by targeted mutagenesis of hydrophobin genes can lead to drastic
C Biomed Central

() 2011 Mosbach et al; licensee BioMed Central Ltd. This is an Open Access article distributed under the terms of the Creative Commons Attribution License (http://creativecommons.org/licenses/by/2.0), which permits unrestricted use, distribution, and reproduction in any medium, provided the original work is properly cited. 
reduction in surface hydrophobicity, resulting in 'easily wettable' phenotypes [2]. In the rice pathogen Magnaporthe oryzae mutants in the class I hydrophobin Mpg1 produced easily wettable conidia and hyphae lacking rodlets, and were defective in appressorium formation and host infection. This was attributed to the inability of the germ tubes to firmly attach to the hydrophobic plant cuticle and to appropriately sense surface features leading to appressorium differentiation $[4,5]$. In the same fungus, the class II hydrophobin Mhp1 was also found to be involved in hyphal surface hydrophobicity and for pathogenesis [6]. The tree pathogen Ophiostoma ulmi produces cerato-ulmin, a class II hydrophobin which is a wilt-inducing toxin. Regarding its role in pathogenesis, a final conclusion has not yet been reached. While toxin-deficient mutants were not affected in pathogenicity, their phenotypes indicated that it contributes to the fitness of the spores of O. ulmi $[7,8]$. Similarly, hydrophobin mutations in the tomato pathogen Cladosporium fulvum did not impair the mutant strains to cause disease [9].

Botrytis cinerea (teleomorph Botryotinia fuckeliana) is a necrotrophic plant pathogenic ascomycete with a wide host range, including economically important fruits, vegetables and ornamental flowers. After colonisation of the host tissue, the fungus forms aerial mycelia that produce large numbers of conidia, which are the main source of new infections. Due to their surface hydrophobicity, conidia adhere easily to the plant surface [10]. This initial adhesion is relatively weak and followed by stronger attachment immediately after emergence of the germ tube [11]. Germ tubes secrete an ensheathing film that appears to mediate adhesion to hydrophobic and hydrophilic substrates. The biochemical composition of the film has been analysed, and was found to consist mainly of carbohydrates and proteins, plus minor amounts of lipids [12]. Germination of B. cinerea conidia has been found to depend both on the availability of nutrients and on physical surface properties. In solutions containing sugars as sole organic nutrients, efficient germination occurs only on a hard surface. In the absence of nutrients, germination can still be induced on hard, hydrophobic surfaces [13]. Induction of germination by hard hydrophobic surfaces has also been described for conidia of other plant pathogenic fungi, namely Colletotrichum graminicola and Phyllosticta ampelicida [14,15]. These data indicate that the hydrophobic surface properties of conidia are a prerequisite for appropriate surface sensing under nutrient-limiting conditions.

In order to test the role of hydrophobins in conidial and hyphal hydrophobicity, and therefore possibly in hydrophobic surface sensing, we performed a systematic search for the presence of hydrophobin genes in the $B$. cinerea genome, analysed their expression, and performed a functional analysis of three hydrophobin genes and a hydrophobin-like gene. Surprisingly, mutants lacking all these genes were found to be phenotypically indistinguishable from the wild type in all parameters tested. Our results challenge the concept that hydrophobins are generally required for the formation of hydrophobic surface layers in conidia and hyphae of higher fungi.

\section{Results}

\section{Cloning and sequence analysis of Botrytis cinerea hydrophobin genes}

In the B. cinerea strain B05.10 genome sequence, three hydrophobin encoding genes were identified. Using Magnaporthe oryzae class I hydrophobin Mpg1 [4] as a query in a blastp search, a protein (BC1G_15273) with weak homology was detected. Its size, arrangement of the eight conserved cysteines, and overall hydropathicity was similar to $M$. oryzae Mpg1 and other class I hydrophobins, and it was called Bhp1 (for 'Botrytis hydrophobin'). Using M. oryzae class II hydrophobin Mhp1 [6] in another blastp query, the $B$. cinerea proteins BC1G_03994 (called Bhp2) and BC1G_01012 (called Bhp3) were found to show significant homologies (E values $\left.<\mathrm{e}^{-10}\right)$. With blastp and tblastn searches using known hydrophobin proteins, no further hydrophobin genes were identified in the $B$. cinerea genome. The identification of hydrophobin encoding genes in fungal genomes is sometimes difficult due to their small size, the variable spacing between the cysteine encoding codons, and their low sequence homologies, in particular among class I hydrophobin genes. In order to identify further candidates for $B$. cinerea hydrophobins, a systematic search was performed in the published genome sequences of $B$. cinerea strains B05.10 and T4. The following search parameters were used: a) Total size of the protein smaller than 250 amino acids; b) Presence of at least 6 cysteines, four of them in a tandem arrangement separated by two further cysteine residues (full cysteine motive of hydrophobins: $C-\left(X_{n}\right)-C C-\left(X_{n}\right)-C-$ $\left.\left(X_{n}\right)-C-\left(X_{n}\right)-C C-\left(X_{n}\right)-C\right)$; c) Prediction of a signal peptide. The search resulted in the identification of six further hydrophobin-like $B$. cinerea proteins, which all had a small size (98-234 aa), and a similar pattern of eight cysteines after manual correction of annotations (Table 1; additional file 1: Table S1). Examination of their hydropathicity revealed that five of these proteins are significantly less hydrophobic within the cysteinerich region when compared to confirmed class I and II hydrophobins (Table 1). Only the protein encoded by BC1G_01003 (called Bhl1, for 'Botrytis hydrophobinlike'), showed a hydrophobicity similar to Bhp1. However, the cysteine spacing of Bhl1 differs somewhat from that of confirmed class I hydrophobins [16] (Table 1), it 
Table 1 Sequence characteristics of $B$. cinerea hydrophobins and hydrophobin-like proteins

\begin{tabular}{|c|c|c|c|c|c|c|c|c|}
\hline Name/predicted class & Size & Spacing of cyst & e residues & & & & & GRAVY \\
\hline Bhp1 (BC1G_15273) & $111 / 93$ & N- 34-C- 7 & -CC- 18 & $-C-15$ & $-C-5$ & -CC- 17 & $-\mathrm{C}-7$ & 0.57 \\
\hline Consensus spacing class I & & N- Xn-C- (5-8) & $-C C-(17-39)$ & $-C-(8-23)$ & $-C-(5-6)$ & $-C C-(6-18)$ & $-C-(2-13)$ & \\
\hline Bhp2 (BC1G_03994) & $98 / 77$ & N- 33-C- 6 & $-\mathrm{CC}-\underline{11}$ & $-C-\underline{16}$ & $-C-8$ & $-\mathrm{CC}-\underline{10}$ & $-C-6$ & 0.42 \\
\hline Bhp3 (BC1G_01012) & $98 / 80$ & N- 34-C- 8 & -CC- 11 & $-C-\underline{16}$ & $-C-8$ & -CC- 10 & $-\mathrm{C}-3$ & 0.30 \\
\hline Consensus spacing class II & & N- Xn-C-(9-10) & -CC- 11 & $-C-\underline{16}$ & $-C-(6-9)$ & -CC- 10 & $-C-(3-7)$ & \\
\hline Bhl1 (BC1G_01003) & $145 / 125$ & N- $60-C-9$ & $-\mathrm{CC}-31$ & $-C-8$ & $-C-7$ & -CC- 16 & $-C-6$ & 0.76 \\
\hline BC1G_02483 & $234 / 211$ & $\mathrm{~N}-82-\mathrm{C}-8$ & $-\mathrm{CC}-7$ & $-C-5$ & $-C-9$ & $-\mathrm{CC}-8$ & $-C-107$ & -0.10 \\
\hline BC1G_03277 & $178 / 160$ & $\mathrm{~N}-111-\mathrm{C}-7$ & $-C C-10$ & $-C-17$ & $-C-8$ & - CC- 12 & $-C-5$ & -0.43 \\
\hline BC1G_04521 & $181 / 157$ & $N-120-C-7$ & -CC- 10 & $-C-10$ & $-C-9$ & $-\mathrm{CC}-4$ & $-C-13$ & 0.01 \\
\hline BC1G_11117 & $109 / 88$ & N- 35-C- 10 & -CC- 15 & $-C-18$ & $-C-8$ & -CC- 11 & $-C-4$ & -0.77 \\
\hline BC1G_12747 & $106 / 86$ & N- 37-C- 3 & -CC- 10 & $-C-13$ & $-C-18$ & $-C C-4$ & $-C-13$ & -0.28 \\
\hline
\end{tabular}

For the three hydrophobins Bhp1 (class I), Bhp2 and Bhp3 (both class II), and for six hydrophobin-like proteins, the cysteine spacing is shown. Consensus cysteine spacings for class I and class II proteins were taken from [16]. The sizes (amino acids) of the unprocessed and processed proteins are indicated. N: N-terminus; $\mathrm{Xn}$ : Undefined number of amino acids; Underlined: Strictly conserved spacing; GRAVY: Grand average of hydropathicity of the region covering the eight cysteines. Positive GRAVY values indicate hydrophobicity [53].

has a distinct hydropathy profile (additional file 2: Figure $\mathrm{S} 1$ ), and it lacks homology to other fungal hydrophobins (data not shown).

Bhp1 is 111 amino acids long and contains eight cysteines with spacing as described for the class I hydrophobin consensus sequence [16]. It shows 30\% identity to Xph1 of the lichen fungus Xanthoria parietina, and 29\% identity to Mpg1 of Magnaporthe oryzae (Figure 1A). The hydropathy plot of Bhp1 shows similarity to that of Mpg1 and of other class I hydrophobins (Figure $1 \mathrm{C}$; data not shown). Bhp2 and Bhp3 are both 98 amino acids long and $27 \%$ identical to each other. Both proteins match the consensus cysteine spacing of class II hydrophobins (Table 1) [16]. Bhp2 shares 37\%, and Bhp3 29\% identity with $M$. oryzae Mhp1 (Figure 1B). The hydropathy plots of Bhp2 and Mhp1 are similar (Figure 1D).

\section{Comparison of hydrophobin genes in $B$. cinerea and Sclerotinia sclerotiorum}

A comparison of the genes that are encoding hydrophobins and hydrophobin-like proteins in the genomes of $B$. cinerea and the closely related $S$. sclerotiorum was performed (additional file 1: Table S1). For all except one (BC1G_12747) of the B. cinerea proteins, apparent orthologues were found in S. sclerotiorum. The proteins encoded by BC1G_11117 and SS1G_01003 are bidirectional best hits in blastp queries; however their overall sequence similarity (33\% identity) is rather low.

\section{Expression of hydrophobin and hydrophobin-like genes during $B$. cinerea development}

To analyse the expression profiles of $b h p 1, b h p 2$ and $b h p 3$, and the six hydrophobin-like genes, RNA from different developmental stages of $B$. cinerea was isolated and analysed by reverse transcription-PCR. As shown in Figure 2A, transcripts of $b h p 1, b h p 2$ and $b h p 3$, as well as the ef $1 \alpha$ gene which was used as positive control, could be detected in mycelia, infected tomato leaves 48 h.p.i. and mature sclerotia of the wild type strain B05.10, as well as in fruiting bodies from the cross of two $B$. cinerea field isolates. Except for $b h p 2$, expression of all these genes was also visible in the conidial state. Generally, expression levels of the three hydrophobin genes appeared to be rather low. Transcripts of the hydrophobin-like genes BC1G_02483, BC1G_03277, BC1G_11117 and BC1G_04521 were also detected in all developmental stages tested, but with apparently variable expression levels. In contrast, expression of BC1G_12747 was largely restricted to sclerotia, and bhl1 transcripts were only observed in fruiting bodies. To estimate the expression levels of the genes more precisely, quantitative RT-PCR was performed (Figure 2B). For each of the genes, expression in conidia was compared to that in the stage(s) that appeared to show strongest expression. Expression of all genes in conidia was rather weak. Highest levels of expression were observed for bhp1 and bhl1 in fruiting bodies, in particular bhp1 reached expression levels similar to actin and ef1 $\alpha$. The increased expression of bhp2, BC1G_02483 and BC1G_12747 in sclerotia was also confirmed.

\section{Targeted deletion of bhp1, bhp2, bhp3 and bh/1}

To analyse their functions, the hydrophobin genes $b h p 1$, $b h p 2$ and $b h p 3$ were consecutively deleted. Hydrophobin single knock-out mutants were constructed by using hygromycin or nourseothricin cassettes for selection. For double knock-out mutants, both cassettes were sequentially used. Finally, for generating a triple 

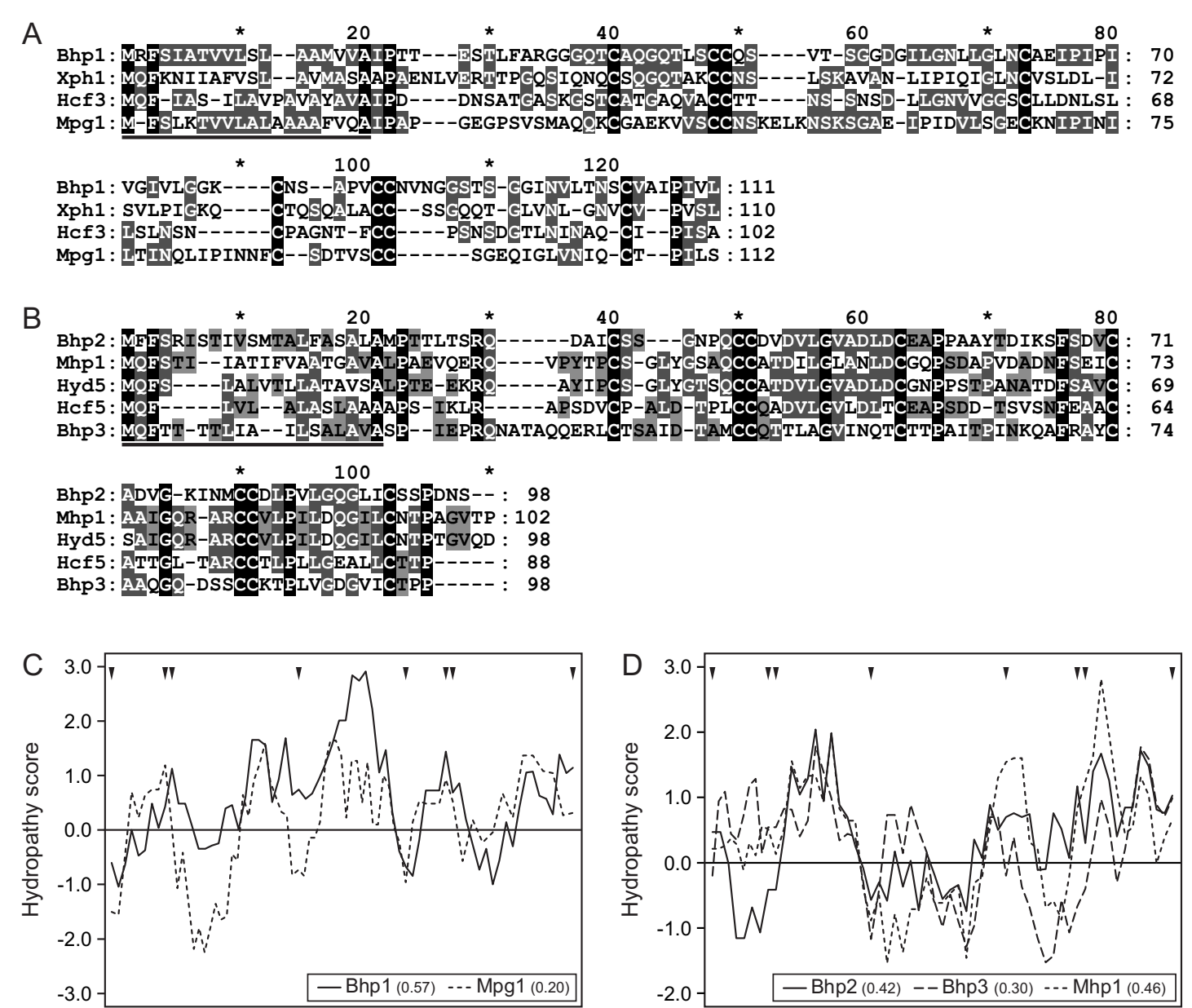

Figure 1 Sequence alignments and hydropathy plots of B. cinerea hydrophobins and confirmed class I and II hydrophobins. A: Amino acid alignment of Bhp1 and class I hydrophobins. B: Amino acid alignment of Bhp2/3 and class II hydrophobins. The signal peptides are underlined. Hcf3 (Acc.: CAD92803) and Hcf5 (Acc:: CAC27408) from Cladosporium fulvum; Hyd5 (Acc.: AAN76355) from Fusarium verticillioides; Mpg1 (Acc.: P52751) and Mhp1 (Acc.: AAD18059) from M. oryzae; Xph1 (Acc.: CAC43386) from X. parietina. C and D: Hydropathy plots with Bhp1 and M. oryzae Mpg1 (left), and with Bhp2, Bhp3 and M. oryzae Mhp1 (right). Hydropathy values were calculated for the sequences covering the eight cysteines (window size for calculation: 7 amino acids). Positive values indicate regions of high hydrophobicity. Positions of cysteine residues are marked by triangles. Grand average of hydropathicity (GRAVY) of the analysed region is indicated in parentheses.

knock-out mutant, a $\Delta b h p 3 / b h p 1$ double mutant was transformed with a $b h p 2$ knock-out construct carrying a phleomycin resistance cassette as a third selectable marker. Additionally, a knock-out mutant of the hydrophobin-like gene bhl1 was created. All transformants were verified by PCR analysis (data not shown), and by RTPCR using cDNA from different developmental stages (Figure 2A). No transcripts of bhp1, bhp2 and bhp3 could be detected in the hydrophobin triple mutant in any of the growth stages tested. In the same way, no transcripts of genes that had been deleted could be amplified from hydrophobin double knock-out strains (additional file 3: Figure S2). The expression levels of the five hydrophobin-like genes BC1G_02483, BC1G_03277, BC1G_11117, BC1G_12747 and BC1G_04521 in the hydrophobin triple mutant appeared to be similar to the wild type, as far as this could be estimated from semiquantitative RT-PCR. Because transcripts of bhl1 could be unambiguously detected only in fruiting bodies (Figure 2A), which were unavailable from $\Delta b h l 1$ mutants, verification of the $\Delta b h l 1$ strain by RT-PCR analysis was not possible.

\section{Growth, differentiation and infection behaviour of the hydrophobin mutants}

The germination rates of hydrophobin knock-out mutants and the wild type strain were analysed under different conditions. As previously shown [13], wild type conidia incubated on glass without nutrients did not germinate to a significant extent, whereas nearly complete 
A

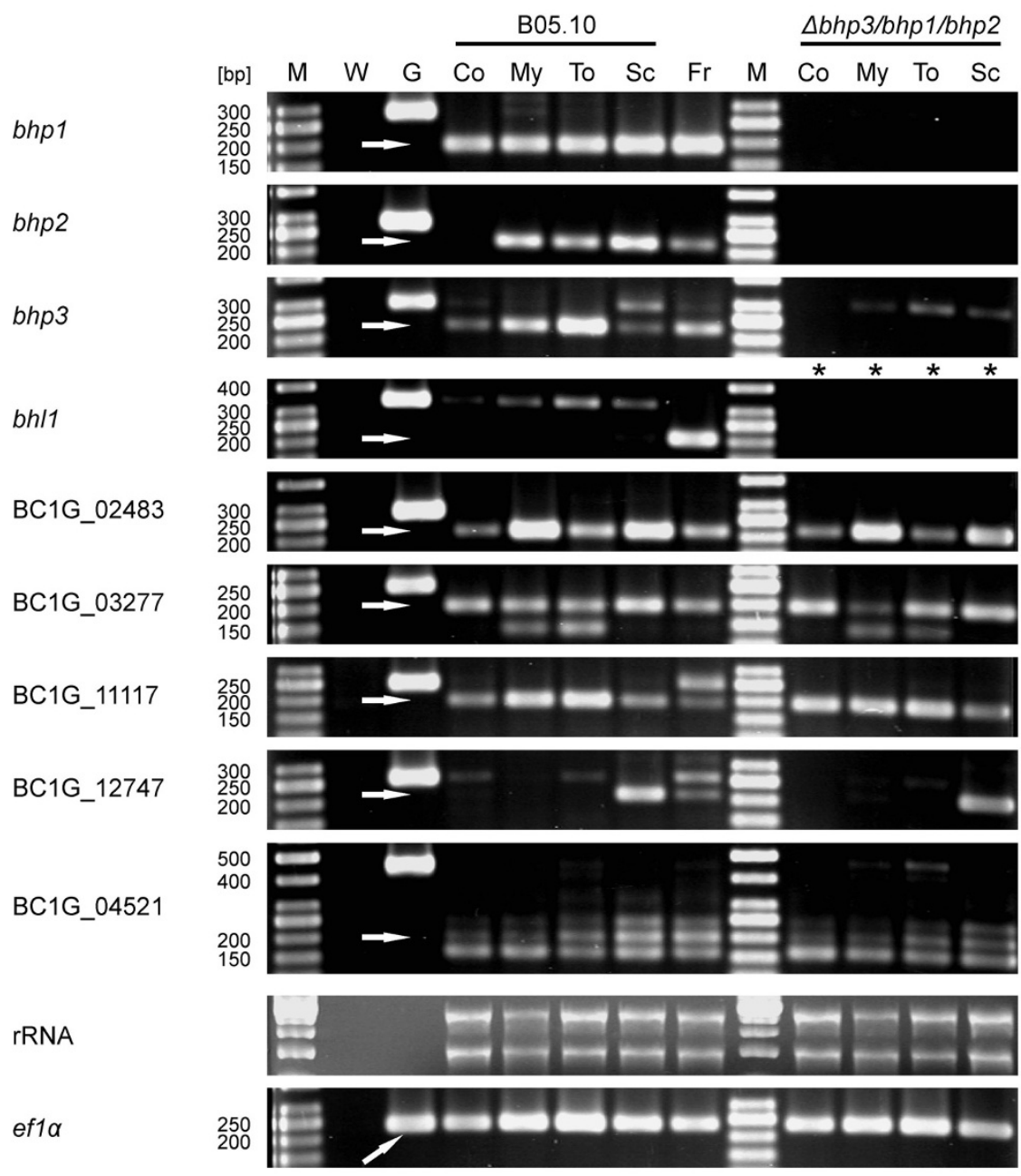

B

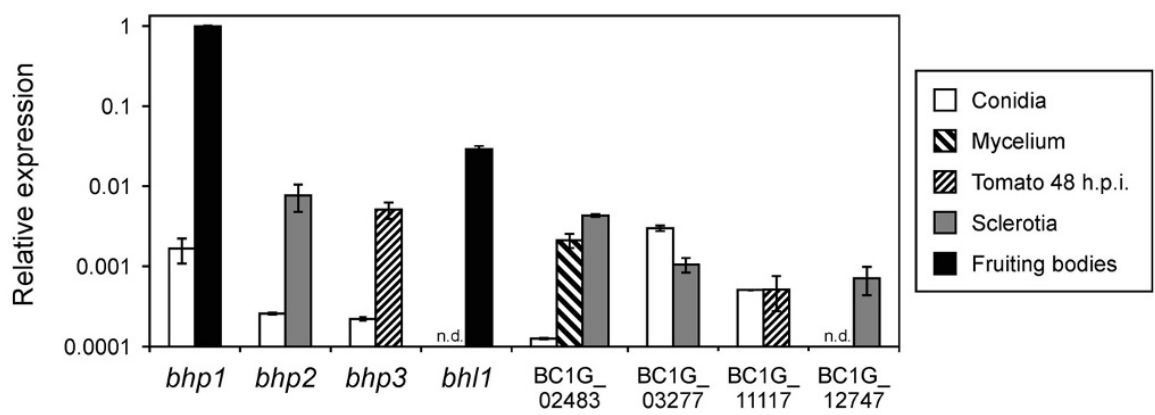

Figure 2 Expression analysis of the hydrophobin genes $b h p 1, b h p 2$ and $b h p 3$, and six hydrophobin-like genes. A: Results of semiquantitative RT-PCR, showing gene expression in different developmental stages of wild type B05.10, the hydrophobin triple mutant $\triangle b h p 3 /$ bhp1/bhp2, and the $\Delta b h / 1$ mutant (lanes with cDNA from $\Delta b h / 1$ labelled with stars). M: Size markers, with relevant sizes indicated [bp]; W: Water control; G: Genomic DNA; Co: Resting conidia; My: mycelium (15 h.p.i.); To: Infected tomato leaves (48 h.p.i.); Sc: Sclerotia; Fr: Fruiting bodies. An EF1 $\alpha$ encoding fragment was amplified as positive control. Arrows indicate positions of bands based on CDNA (in case of ef1 $\alpha$, the size of cDNA and genomic DNA is identical). Undiluted first-strand cDNA was amplified with 35 cycles, except for ef1 $\alpha$ cDNA, which was amplified from 1:10 diluted first-strand CDNA. The multiple bands obtained with BC1G_04521-specific primers might be due to different splicing variants. The weak bands indicating the presence of wild type bhp3 genomic DNA in the triple hydrophobin mutant seem to result from the presence of few remaining, non-transformed nuclei. B: Results of real-time RT-PCR, showing gene expression in conidia and selected growth stages of strain B05.10, except for fruiting bodies which were from a cross of $B$. cinerea field isolates. Hydrophobin expression levels are shown relative to the mean of actin and efl $\alpha$ expression. 
germination occurred in the presence of $10 \mathrm{mM}$ fructose. On a hydrophobic polypropylene surface, conidia germinated to $90 \%$. Neither the single nor the double nor the triple hydrophobin mutants showed any difference in their germination behaviour when compared to the wild type (Figure 3A). To test the viability of the conidia under long term storage conditions, they were incubated for up to 12 weeks at $20^{\circ} \mathrm{C}$ and $32 \%$ humidity in the dark. Samples were taken at regular intervals, and tested for germination of the conidia in full medium. No significant decrease in germination rates were observed for any of the mutant strains within this time period (data not shown), indicating that hydrophobin mutants of $B$. cinerea do not display obvious defects in conidial viability.

The mutants $\Delta b h p 2, \Delta b h p 3 / b h p 1$ and $\Delta b h p 3 / b h p 2$, were also tested in a radial growth assay on TMA and Gamborg glucose agar, in the presence of high temperature stress $\left(28^{\circ} \mathrm{C}\right.$ on TMA), and under salt stress $(0.5 \mathrm{M}$ $\mathrm{NaCl}$ in Gamborg glucose agar). Again, no differences in growth rates of hydrophobin mutants and the wild type strain were observed (data not shown).

In Verticillium dahliae, the class II hydrophobin VdhI has been described to be required for microsclerotia formation [17]. The increased expression of bhp2 in sclerotia indicated that it could play a role in sclerotia formation or function. To induce sclerotia formation in the wild type strain and the hydrophobin mutants, conidial suspensions were inoculated on Gamborg glucose agar and incubated for 28 days in the dark. As shown for the hydrophobin triple mutant in Figure 3B, all of the hydrophobin mutants produced sclerotia in similar size and number as the wild type. When water droplets were applied to wild type and mutant sclerotia, they remained on the surface, indicating a hydrophobic nature of the sclerotial surface (not shown). The functional integrity of the sclerotia in the triple mutant and the $\Delta$ bhl1 mutant was confirmed by a germination test (Figure 3C). Furthermore, microconidia and microconidia-forming structures were observed in close proximity to sclerotia in the wild type and in the mutants (Figure 3D; not shown for $\Delta b h l 1$ mutant).

$\Delta m p g 1$ mutants of $M$. oryzae are strongly impaired in their virulence on rice plants $[4,18]$. The $B$. cinerea hydrophobin mutants were therefore tested for host plant invasion and infection abilities. On onion epidermis cell layers, wild type strain B05.10 usually forms short germ tubes before penetrating into the epidermal layer. The hydrophobin mutants analysed in this test penetrated into epidermis cells with the same efficiency as the wild type (Figure 3E; not shown). For plant infection tests, one $\Delta b h p 1$, one $\Delta b h p 2$, one $\Delta b h p 3$, three $\Delta b h l 1$, three double and three transformants of the triple knock-out mutant were used to inoculate detached tomato leaves. No significant differences in the kinetics of lesion development and expansion were observed between any of the mutants and the wild type (Figure 3F, not shown). Similar infection tests performed with Gerbera and rose petals also did not reveal any phenotypic differences between the strains (not shown).

\section{Surface properties of conidia of hydrophobin mutants are indistinguishable from the wild type}

In many fungi, deletion mutants lacking individual hydrophobins, especially of class I, show 'easily wettable' phenotypes, due to the reduction in surface hydrophobicity of mycelia and conidia. To test the $B$. cinerea hydrophobin mutants for a similar phenotype, they were inoculated onto rich nutrient media and grown for 12 days to obtain densely sporulating mycelium. Droplets of water and SDS solutions at different concentrations were carefully overlaid and incubated for up to 24 hours at $20^{\circ} \mathrm{C}$ in a humid chamber. As illustrated in Figure $3 \mathrm{H}$, all of the droplets remained on the surface of sporulating mycelia of the wild type and the mutants. Even after 24 hours of incubation at high humidity, the droplets were still present, except that the droplets with 5,10 and $18 \%$ SDS had partially sunken into the mycelia. Similarly, wettability tests performed on aerial hyphae of non-sporulating mycelia revealed no significant differences between the wild type and a hydrophobin triple mutant: Both strains were wetted by $0.2 \%$ SDS within a few minutes, while droplets of water remained on the mycelial surface for up to 7 hours (Figure 3G).

Conidia and hyphae of several fungi have been shown to be coated with hydrophobin layers that form typical rodlet-shaped crystalline structures. These layers are often absent in hydrophobin class I mutants [4,19-21]. Previous electron microscopy studies of $B$. cinerea conidia did not reveal evidence for rodlet-like surface structures [22]. To examine whether or not conidia of $B$. cinerea hydrophobin mutants were affected in surface morphology, scanning electron microscopy (SEM) with dryly harvested spores was performed. Neither the hydrophobin triple knock-out mutants nor the wild type conidia were covered with rodlet-shaped structures, and no differences were observed between the strains (Figure 4A-C). When wild type conidia were treated with hexane, only small changes in their surface structures were observed. Similarly, spores washed for several times with water left the conidial surface structures rather intact. In contrast, chloroform treatment had a drastic effect on the appearance of the conidial surface, leading to almost complete abrasion of the spinose surface (Figure 4D-G).

\section{Discussion}

The genomes of filamentous basidiomycetes and ascomycetes generally contain multiple hydrophobin 
A

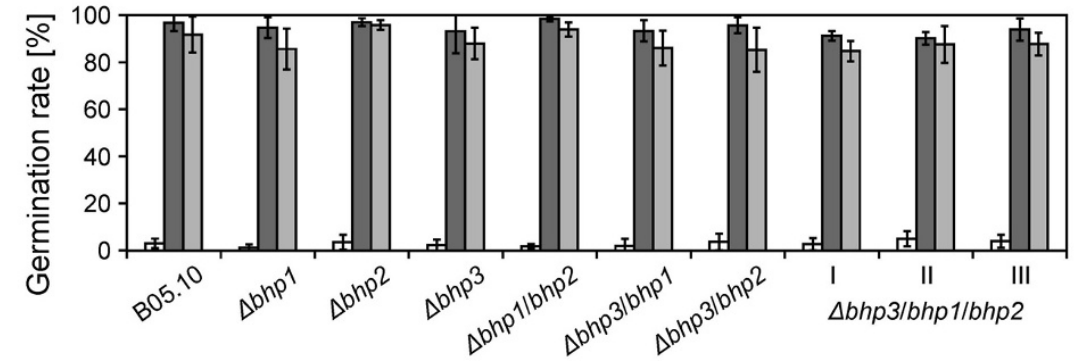

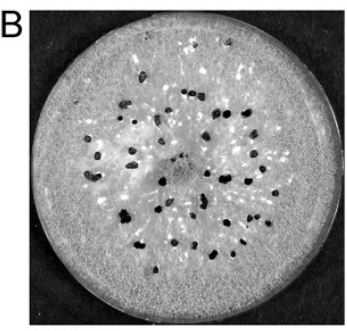

B05.10

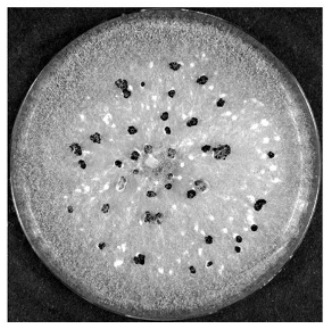

$\Delta b h p 3 / b h p 1 / b h p 2$
C

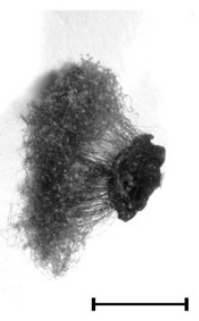

B05.10

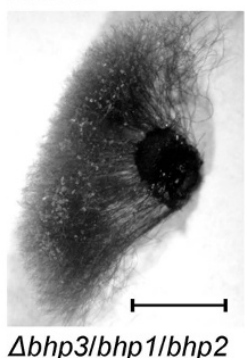

D

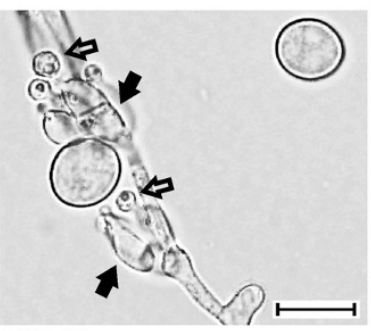

B05.10

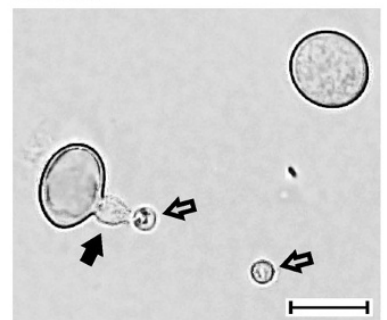

$\Delta b h p 3 / b h p 1 / b h p 2$

$\mathrm{F}$
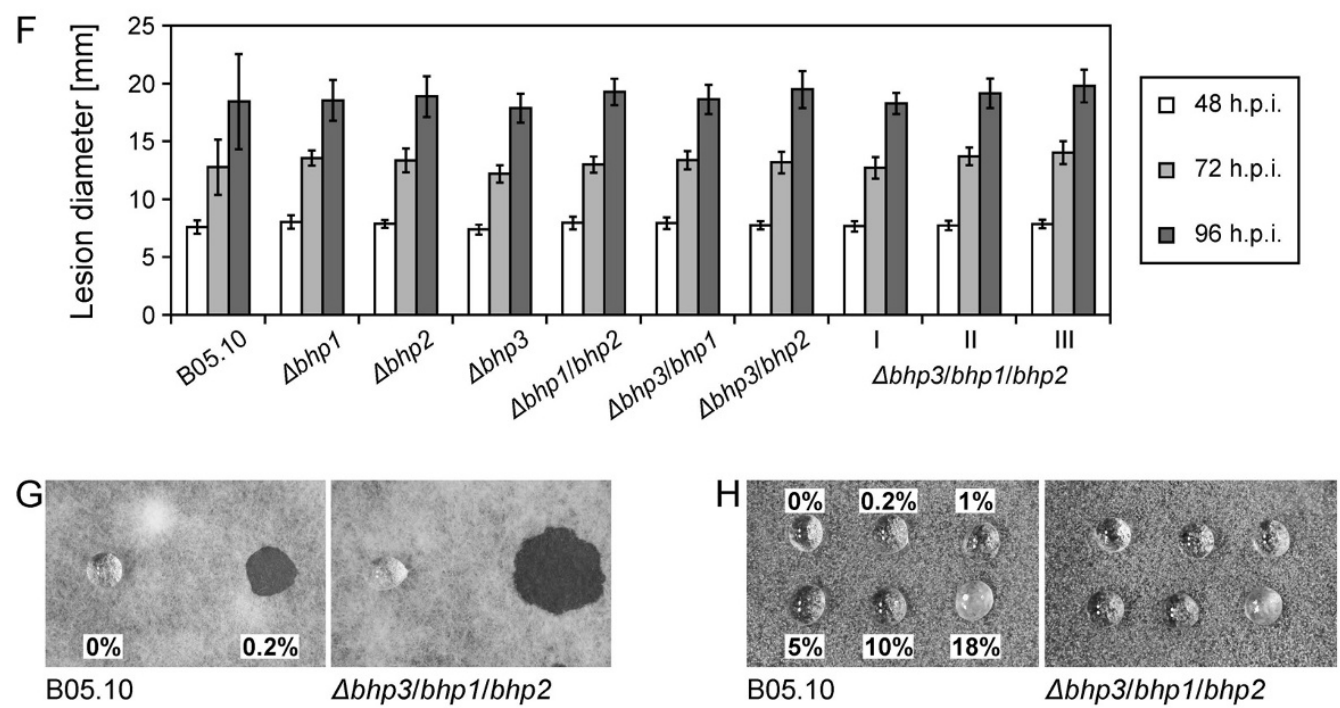

Figure 3 Phenotypic characterisation of hydrophobin mutants. A: Germination rates under different conditions, 24 h.p.i. I, II, II: Three transformants of hydrophobin triple mutant. Standard deviations are shown. B: Sclerotia formation on Gamborg agar plates. C: Germinated sclerotia with conidiophores and macroconidia (scale bar: $3 \mathrm{~mm}$ ). D: Microconidia (hollow arrows) produced on phialides (filled arrows). Phialides were observed on branching hyphae and on macroconidia of B05.10 and the triple mutant (scale bar: $10 \mu \mathrm{m}$ ). E: Penetration into heat-killed onion epidermal cell layers (16 h.p.i). Fungal structures at the epidermal surface were stained with trypan blue (scale bar: $25 \mu m$ ). F: Lesion formation on detached tomato leaves. Standard deviations are shown. G: Wettability test with water and 0.2\% SDS on non-sporulating mycelia. Pictures were taken after $3 \mathrm{~h}$. H: Wettability test with SDS solutions on sporulating aerial mycelia. Pictures were taken after $7 \mathrm{~h}$. 

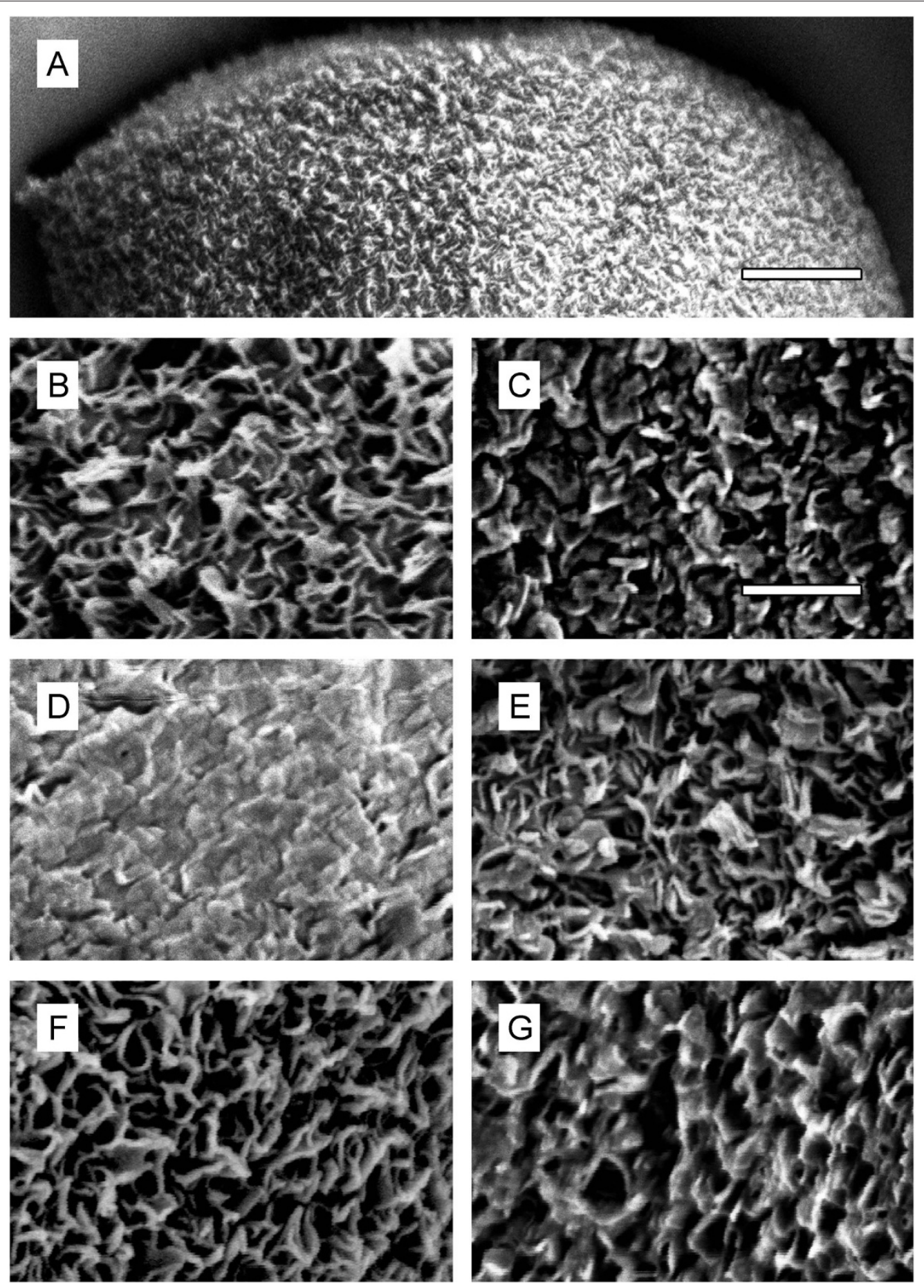

Figure 4 Scanning electron microscopy of $B$. cinerea conidia. A: Overview showing the jagged spore surface (scale bar: $1 \mu \mathrm{m})$. B, C: Higher magnifications, showing irregular jags of wild type (B) and triple mutant (C) spores. D: After treatment of wild type conidia with chloroform, the jags appeared abraded. E: Treatment of wild type conidia with hexane does not cause obvious changes in surface topography. F, G: Repeated washing with water caused minor abrasions of the spiny surface of wild type (F) and triple mutant $(G)$ conidia. Scale bar for higher magnifications in B-G: $250 \mathrm{~nm}$. 
genes [2]. In contrast, hydrophobin genes have not been found in yeasts, for example Cryptococcus neoformans, Saccharomyces cerevisiae, Schizosaccharomyces pombe, and Candida albicans. Despite their important role, hydrophobins are not the only proteins that confer hydrophobic properties to fungal cell walls. The basidiomycete Ustilago maydis encodes a single hydrophobin, Hum2, and a much larger protein called Rep1. While Hum2 plays only a minor role, the peptides released from Rep1 during secretion are mainly responsible for conferring surface hydrophobicity to aerial hyphae in this fungus $[23,24]$.

Our search in the annotated genome sequences of B. cinerea strains B05.10 and T4 has revealed the presence of three unambiguous hydrophobins, and a total of six hydrophobin-like proteins, according to the criteria defined in the results. For all except one of these genes, homologues in the closely related Sclerotinia sclerotiorum have been identified. In contrast, homologues in other fungi were only found for the three hydrophobins and for the hydrophobin-like protein BC1G_02483. BC1G_02483 was unusual because its size (234 amino acids), the dense spacing of the 8 consensus cysteines, and the presence of 4 additional $\mathrm{N}$-terminal cysteines. The three hydrophobins share typical properties of class I (Bhp1) and class II (Bhp2, Bhp3) proteins. Expression of $b h p 1, b h p 2$ and $b h p 3$ was found to be low in conidia and mycelium. This was confirmed by a qRTPCR analysis that showed generally low expression levels of the three hydrophobin genes and the hydrophobinlike genes in conidia. However, Bhp1 was found to be strongly upregulated in fruiting bodies. This is supported by EST data from a cDNA library from apothecia of B. cinerea. Among 3189 ESTs, 15 (0.5\%) were found to represent Bhp1 mRNA, while no ESTs of other hydrophobin sequences were identified in the apothecial library (J. Amselem and M.-H. Lebrun, personal communication). Our RT-PCR data did not provide evidence that deletion of the hydrophobin genes significantly changes the expression level of any other hydrophobin (-like) genes analysed in this study (Figure 2A; additional file 3: Figure S2).

Several of the hydrophobin (-like) protein encoding genes showed their highest expression levels either in sclerotia (bhp2, BC1G_12747) or in fruiting bodies (bhp1, bhl1). While we did not find any effects of the $\Delta b h p 2$ mutants on sclerotia formation, the role of BC1G_12747 for sclerotia remains to be determined. Since we have not yet been able to perform crosses with B. cinerea in our laboratory, the role of Bhp1 and Bhl1 in fruiting body development and function also remains to be clarified. The strong upregulation of $b h p 1$ and the apparently exclusive expression of bhl1 in fruiting bodies suggest that these genes might play a role during sexual development.
Using three different resistance markers for selection, mutants that lacked one, two, and all three hydrophobin genes $b h p 1, b h p 2$ and $b h p 3$ were generated. To our knowledge, this is the first triple knock-out mutant described for $B$. cinerea. It was difficult to isolate because phleomycin is less suited for transformant selection compared to the commonly used hygromycin and nourseothricin, because of the growth of many false transformants. In addition to the hydrophobins, the hydrophobin-like gene bhl1 was knocked out. The resulting mutants were analysed for a variety of parameters of growth, differentiation and plant infection. In no case, significant differences between the phenotypes of wild type and mutant strains were observed. Specifically, the mutants showed wild type-like surface hydrophobicity of conidia and hyphae, and normal conidial surface structures when viewed by scanning electron microscopy. In agreement with a previous study [22], there is no evidence for the presence of a rodlet-like surface layer on $B$. cinerea conidia. This finding is in contrast to a variety of other fungi which have hydrophobin-coated cell walls surrounding conidia, germ tubes or aerial hyphae [2]. Interestingly, hydrophobin layers have been recently found to protect conidia from immune recognition [25]. While airborne conidia of Botrytis are usually less prevalent compared to the major genera Cladosporium and Alternaria, they have significant allergenic potential [26]. It is possible that this might be due to the absence of hydrophobin layers in $B$. cinerea conidia.

Our data indicate that $B$. cinerea hydrophobins do not play a major role in the hydrophobic coating of spores and hyphal wall, and thus are not important for attachment to hydrophobic surfaces or formation of aerial hyphae. Although we cannot completely exclude that any of the other five hydrophobin-like proteins listed in additional file 1: Table $\mathrm{S} 1$ are relevant in this respect, they are more hydrophilic than Bhp1, Bhp2, Bhp3 and Bhl1 and therefore not very likely to represent hydrophobins. As mentioned before, we do not exclude the possibility that Bhp1 or Bhl1 are involved in sexual development. Hydrophobins are known to be important for the formation of fruiting bodies in basidiomycetous mushrooms such as Agaricus bisporus and Schizophyllum commune [2]. In the chestnut blight fungus Cryphonectria parasitica, the class II hydrophobin cryparin has been shown to cover the walls of fruiting bodies and to be required for normal fruiting body development [27].

Because several hydrophobins are encoded in the genomes of filamentous fungi, it is difficult to fully assess their roles and to exclude complimentary functions. In the tomato pathogen Cladosporium fulvum, six hydrophobins have been identified. Using single mutations, one of them (Hcf1) was found to be required for spore 
surface hydrophobicity, another one (Hcf6) seems to be involved in adhesion of germinating spores to glass surfaces [28]. An attempt to assess the function of all hydrophobins simultaneously by multiple RNAi silencing failed to result in complete knock-down of the genes [29]. In Fusarium verticillioides, five hydrophobin genes (hyd1-hyd5) have been identified up to now in the genome. Phenotypical analysis of single mutants in these genes and of a hyd1/hyd2 double mutant revealed that hyd 1 and hyd2 are required for normal microconidia formation, but did not provide evidence for a role of these hydrophobins in growth, infection behaviour, and mycelium hydrophobicity [16]. This indicates that in some fungi, including $B$. cinerea and F. verticillioides, hydrophobins play only a minor - if any - role in generating cell wall surface hydrophobicity. However, they might serve other, as yet unknown functions.

By far not all fungal spores contain superficial rodlet layers. For example, they are missing in the urediospores of rust fungi [30], and conidia of several powdery mildews [31]. Rust urediospores have been shown to be covered with a layer of lipids that can be extracted with organic solvents, leading to a significantly decreased hydrophobicity, and increased attachment to hydrophilic surfaces [32,33]. Surface bound lipids, containing hydrocarbon and fatty acid constituents, have been described for spores of several but not all fungal species analysed. The lack of visible effects of hexane treatment on the surface structure of $B$. cinerea conidia indicates that simple lipids are not a major surface component of these spores. Alternatively, proteins other than hydrophobins could play a role in conferring surface hydrophobicity. In Stagonospora nodorum, preformed surface glycoproteins have been proposed to play a role in the attachment of conidia to hydrophobic surfaces [34]. In the yeasts $S$. cerevisiae and C. glabrata, cell wall surface proteins called flocculins and adhesins, are involved in adhesion to various surfaces and in biofilm formation; their expression has also been correlated with an increased hydrophobicity of the cell surfaces $[35,36]$. Adhesin-like proteins are also encoded in the genomes of filamentous ascomycetes; however, their function remains to be analysed [37].

\section{Conclusions}

Hydrophobins are very important for growth and differentiation of higher filamentous fungi, but their roles differ between different species. In some fungi, including B. cinerea, hydrophobic surface properties appear to be provided by as yet unknown mechanisms, different from the amphipathic layers formed by hydrophobins. It is evident that our knowledge about the molecules that cover the surfaces of fungal spores and determine their physicochemical properties is still far from being complete.

\section{Methods}

Cloning of the B. cinerea bhp1, bhp2, bhp3 and bh/1 genes and knock-out constructs

B. cinerea hydrophobin genes bhp1, bhp 2 and $b h p 3$ including flanking regions of 392-771 bp were amplified with primers (Table 2) BHP1-1/2, BHP2-1/2 and BHP3$1 / 2$ (introducing $\mathrm{BamHI}$ restriction sites at both ends of the PCR product) respectively from genomic DNA, and cloned into pBS(+) (Stratagene, La Jolla, USA). Subsequently, an inverse PCR was performed, using primers BHP1-3/4, BHP2-3/4 and BHP3-3/4. After digestion with $E c o$ RI, the products were ligated with a hygromycin resistance cassette amplified by PCR from pLOB1 [38] with primers $\mathrm{KO}-\mathrm{Hyg} 1-\mathrm{EcoRI} / \mathrm{KO}-\mathrm{Hyg} 2-\mathrm{EcoRI}$, resulting in the plasmids pBHP1-Hyg, pBHP2-Hyg and pBHP3Hyg. Knock-out constructs containing a nourseothricin resistance cassette were produced by replacing the hygromycin resistance cassette with a BamHI/EcoRI restriction fragment from plasmid pNR2 $[39,40]$, resulting in plasmids pBHP1-Nat and pBHP2-Nat. For the creation of hydrophobin triple mutants, a phleomycin resistance cassette from pAN8-1UM [41] was used. The gpdA promoter in pAN8-1UM was replaced by an oliC promoter fragment from pBHP1-Hyg using EcoRI/NcoI restriction sites. The modified phleomycin resistance cassette was amplified with primers T7/TtrpC-revEcoRV. The PCR product was digested with EcoRI/ EcoRV and ligated with digested pBHP2-Hyg to replace the hygromycin resistance cassette, resulting in $\mathrm{pBHP2}$ Phleo. For generation of the bhl1 knock-out construct, the gene was amplified with primers BHL1-1/2 (introducing $B a m \mathrm{HI}$ and XhoI sites), and cloned into pBSKS(+) (Stratagene). Inverse PCR was performed using primers BHL1-3/4 (introducing SmaI and HindIII sites), and the products ligated with the hygromycin resistance cassette cut out from pLOB1 using SmaI and HindIII, resulting in pBHL1-Hyg. Knock-out constructs for transformation were either amplified by PCR or cut out of the plasmid by digestion with BamHI.

\section{DNA and RNA preparation, CDNA synthesis and RT-PCR}

Genomic DNA from B. cinerea strains was isolated as described [42]. Fungal RNA was purified, including a DNase treatment, using the NucleoSpin ${ }^{\circledR}$ RNA Plant Kit (Macherey-Nagel, Düren, Germany). cDNA was synthesised with the Thermo Scientific Verso ${ }^{\mathrm{TM}}$ cDNA Synthesis Kit (ABgene House, Surrey, UK). For preparation of 15 hours old mycelium, $9 \mathrm{~cm}$ Petri dishes were inoculated with $2 \times 10^{6}$ conidia in $22.5 \mathrm{ml}$ Gamborg medium (Duchefa, Haarlem, The Netherlands) with $10 \mathrm{mM}$ $\mathrm{KH}_{2} \mathrm{PO}_{4}$ and $10 \mathrm{mM}$ fructose, $\mathrm{pH}$ 5.5. The mycelium was harvested using a tissue cell scraper, and washed once with ice cold water before RNA preparation. Mature, fresh fruiting bodies from a laboratory cross of 
Table 2 Primers used in this study

\begin{tabular}{|c|c|}
\hline BcAct-RT-for & TCTGTCTTGGGTCTTGAGAG \\
\hline BcAct-RT-rev & GGTGCAAGAGCAGTGATTTC \\
\hline BCEF-RT1 & ATGCTATCGACCCTCCTTCC \\
\hline BCEF-RT2 & GTTGAAACCGACGTTGTCAC \\
\hline BHL1-1 & CCGGGATCCGGGAATCTATCTGATAGCCAGTCAGTC \\
\hline BHL1-2 & GCACTCGAGGACGAGCTCTCCATGTCGTTTC \\
\hline BHL1-3 & ATACCCGGGACATGGTGTTGCTTGGTATGGTATGG \\
\hline BHL1-4 & TCGCAAGCTITCATCTGGATGAAGCGGAGTCG \\
\hline BHL1-Screen 1 & GCACAAGTATCTCGCTTCGGGTTC \\
\hline BHP1-1 & AAGGATCCACGTGGCAAAAGTGACTCTATCTA \\
\hline BHP1-2 & AAGGATCCATTTCTCAAGCTCTCCAAGTATC \\
\hline BHP1-3 & GAGAATTCTTGAATATAGGGAGGAAGTCGTC \\
\hline BHP1-4 & GAGAATTCTGCCATTCCAATCGTTCTCTA \\
\hline BHP1-Screen 1 & ACGAGTTATCAGCCGCGTAG \\
\hline BHP2-1 & AAGGATCCACGGGGCACATCACCATAGA \\
\hline $\mathrm{BHP2-2}$ & AAGGATCCTGCTGCTCCGCAAAAGTCACA \\
\hline BHP2-3 & GAGAATTCGTTGTTITCTTGAAGTTTGTTGTGA \\
\hline BHP2-4 & GAGAATTCGTTCTCCAGATAATTCATAGAGGAT \\
\hline BHP2-Screen 1 & GGCCCTTCTAAGAGCACTAC \\
\hline BHP2-Screen2 & GCTGGGCTATATTGACCATC \\
\hline BHP3-1 & AAGGATCCTGCCCGCCATACATACACCT \\
\hline BHP3-2 & AAGGATCCAGCCACAGTCTCCCTCAATCA \\
\hline BHP3-3 & GAGAATTCAAGATGAGATGATGGATGAAGGAT \\
\hline BHP3-4 & GAGAATTCGCCGATTGTGATGGAAGTCTG \\
\hline BHP3-Screen 1 & CGGACTTGGCACCTACTTAC \\
\hline KO-Hyg1-EcoRl & GTGAATTCTGCAGCTGTGGAGCCGCATTC \\
\hline KO-Hyg2-EcoRl & CTGAATTCCATGAATTGAAGCGGCACTGGC \\
\hline OliC-inv & GATCGATTGTGATGTGATGGAG \\
\hline Phleo-Screen & CGGAACGGCACTGGTCAACTTGG \\
\hline $\mathrm{T7}$ & GTAATACGACTCACTATAGGGC \\
\hline TtrpC-rev-EcoRV & GCCGATATCCGGCCGCTCTAGAAAGAAG \\
\hline TubB-inv & AGTAGATGCCGACCGGGATC \\
\hline 01003-RT-for & CCTACCGCTCTAACAACAAC \\
\hline 01003-RT-rev & TTCCAACACCGGGCAATAC \\
\hline 01012-RT-for & CACAACCACCACACTTATCG \\
\hline 01012-RT-rev & TCCTTGAGCAGCACAGTATG \\
\hline 02483-RT-for & ACTTGTGCCTCGAATGATGG \\
\hline 02483-RT-rev & ATGAAGGAGTGACGGATTGG \\
\hline 03277-RT-for & TGTTGCGGAAGTCATCGAAG \\
\hline 03277-RT-rev & TCGGAATTCGTTGCGATTGG \\
\hline 03994-RT-for & TCAGCATGACTGCCCTATTC \\
\hline 03994-RT-rev & GAAGATCGCAGCACATGTTG \\
\hline 04521-RT-for & TGATGGGTTGGTTCCCTITG \\
\hline 04521-RT-rev & GGGTTAGGATTGCAGCAGTATG \\
\hline 11117-RT-for & TITGTGGCGGTAATGGCATC \\
\hline 11117-RT-rev & GTTCGTCCACAGTGGTTATC \\
\hline
\end{tabular}

Table 2 Primers used in this study (Continued)

\begin{tabular}{ll}
\hline 12747-RT-for & TTCCTCACTCAAGCCCTCCTAAC \\
\hline 12747-RT-rev & ATCGGCATCGTAGAGCAATC \\
\hline $15273-$ RT-for & GTCGTTGCTATTCCCACTAC \\
\hline $15273-$ RT-rev & ATTTGCCTCCGAGCACGATAC \\
\hline
\end{tabular}

Introduced restriction sites are underlined.

two B. cinerea field strains were harvested after 7 months, plunge frozen in liquid nitrogen, and lyophilized before RNA preparation (kindly provided by Sabine Fillinger, INRA AgroParisTech). RT-PCR was performed as described [43], using the primers 01003-RT-for/rev, 01012-RT-for/rev, 02483-RT-for/rev, 03277-RT-for/rev, 03994-RT-for/rev, 04521-RT-for/rev, 11117-RT-for/ rev, 12747-RT-for/rev and 15273-RT-for/rev for detection of hydrophobin (-like) gene transcripts and BcEFRT1/2 for amplification of an ef1 $\alpha$ fragment as control (Table 2). Real-time RT-PCR was performed as described [44], using actin (primers BcAct-RT-for/rev) and ef1 $\alpha$ as control. Expression of BC1G_04521 was not analysed by real-time RT-PCR, because of the multiple bands obtained by semiquantitative RT-PCR.

\section{Transformation of $B$. cinerea and screening of transformants}

Two protocols were used for transformation of B. cinerea. Hydrophobin single and double knock-out mutants were produced according to the first method [45] and selected with $40 \mu \mathrm{g}$ hygromycin B ml${ }^{-1}$ (Duchefa, Haarlem, The Netherlands) or $50 \mu \mathrm{g}$ nourseothricin $\mathrm{ml}^{-1}$ (Werner BioAgents, Jena, Germany) immediately added to the protoplasts in $\mathrm{SH}$ agar $(0.6 \mathrm{M}$ sucrose, $5 \mathrm{mM}$ Tris- $\mathrm{HCl} \mathrm{pH} 6.5,1 \mathrm{mM}\left(\mathrm{NH}_{4}\right) \mathrm{H}_{2} \mathrm{PO}_{4}, 0.8 \%$ bacto-agar). Generation of triple knock-outs was achieved with a second protocol as described [46], except that the complete transformation mixture was added to $200 \mathrm{ml}$ of either $\mathrm{SH}$ agar (pH 7.3) or CzapekDox agar (pH 7.3, with $1 \mathrm{M}$ sorbitol) containing $20 \mu \mathrm{g}$ phleomycin $\mathrm{ml}^{-1}$ (Zeocin ${ }^{\mathrm{TM}}$; InvivoGen, San Diego, USA). For selective growth of transformants, HA medium $(1 \%[\mathrm{w} / \mathrm{v}]$ malt extract, $0.4 \%$ glucose $[\mathrm{w} / \mathrm{v}], 0.4 \%$ yeast extract $[\mathrm{w} / \mathrm{v}], \mathrm{pH} 5.5,1.5 \%$ agar) with $70 \mu \mathrm{g}$ hygromycin $\mathrm{B} \mathrm{ml}^{-1}$ or $85 \mu \mathrm{g}$ nourseothricin $\mathrm{ml}^{-1}$ for hydrophobin single and double mutants, and Czapek-Dox agar ( $\mathrm{pH} 7.3$ ) with $50 \mu \mathrm{g}$ phleomycin $\mathrm{ml}^{-1}$ for triple knock-outs was used. Transformants were screened for homologous integration of knock-out constructs (primers for hygromycin resistance cassettes: BHP2Screen1/TubB-inv, BHP3-Screen1/OliC-inv, BHL1Screen1/TubB-inv; primers for nourseothricin resistance cassettes: BHP1-Screen1/OliC-inv, BHP2-Screen1/OliC- 
inv; primers for phleomycin resistance cassette: BHP2Screen1/Phleo-Screen) and for the absence of wild type hydrophobin sequences (primers BHP1-1/2, BHP2-1/2 or BHP2-Screen1/BHP2-Screen2, BHP3-1/2, BHL1Screen1/01003-RT-for; Table 2).

\section{Tests for germination, growth parameters and infection}

Germination of conidia was tested on glass and on polypropylene surfaces in triplicates as described [13], either in water or with $10 \mathrm{mM}$ fructose as a carbon source. Radial growth tests were performed once on TMA and Gamborg agar $(0.305 \%$ [w/v] Gamborg B5 basal salt mixture [Duch-

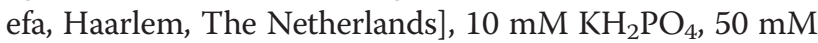
glucose, $\mathrm{pH}$ 5.5, $1.5 \%$ agar). The agar plates $(9 \mathrm{~cm}$ diameter) were inoculated with $10 \mu \mathrm{l}$ suspensions of $10^{5}$ conidia ml ${ }^{-1}$ in water, and incubated at $20^{\circ} \mathrm{C}$ in the dark for 3 days. TMA plates were also incubated at $28^{\circ} \mathrm{C}$ to induce heat stress. The differences in growth radius between days 2 and 3 were determined. Sclerotia formation of the mutants was tested twice on Gamborg agar [47], except that sclerotia were allowed to ripen for additional 14 days in the dark. Microconidia were collected from mycelium close to the sclerotia. The ability of mutants to penetrate into host tissue was determined once on heat-inactivated onion epidermis fragments. Infection tests were performed in triplicates on detached tomato leaves, and on gerbera and rose petals, as described previously [13]. To test sclerotia for germination, they were collected from six weeks old agar plates, rinsed for one minute in $70 \%[\mathrm{v} / \mathrm{v}]$ ethanol, and washed twice for 1 minute with sterile water. After transfer into Petri dishes filled with wet, sterile vermiculite, the sclerotia were frozen for 24 hours at $-8.5^{\circ} \mathrm{C}$ and subsequently incubated at $20^{\circ} \mathrm{C}$ for one week under ambient light.

\section{Test for mycelium wettability}

To obtain sporulating mycelium, HA and tomato malt agar plates were inoculated with a spore suspension and incubated for 12 days at ambient light. To produce nonsporulating mycelium, tomato malt agar plates were incubated for 4 days in a humid box in the dark. Aerial mycelia were overlaid with $20 \mu \mathrm{l}$ droplets containing $50 \mathrm{mM}$ EDTA and different concentrations of SDS [6], and incubated for up to $24 \mathrm{~h}$ in a humid box. Tests were performed in duplicates. Mycelia were evaluated as not wetted, if the droplets remained visible and were not absorbed by the aerial hyphae after the indicated incubation times.

\section{Scanning electron microscopy of $B$. cinerea conidia}

Dry conidia from hydrophobin mutant strains were harvested from sporulating mycelium. For low-temperature scanning electron microscopy (LTSEM) spores were mounted on sticky sample holders and plunge-frozen in nitrogen slush. Samples were transferred into the Alto 2500 (Gatan, Oxford, UK) vacuum preparation chamber (pressure $<2 \times 10^{-4} \mathrm{~Pa}$ ). Next they were sputter-coated with a $10 \mathrm{~nm}$ platinum layer prior to transfer on the SEM cryostage built into an S-4700 field emission scanning electron microscope (Hitachi, Tokyo, Japan). SEM micrographs were digitally recorded after samples were stabilised at $148 \mathrm{~K}$ at an acceleration voltage of $3 \mathrm{kV}$.

\section{Bioinformatic analyses}

Nucleotide and amino acid sequences of the $B$. cinerea hydrophobins were taken from the databases of the Broad Institute (http://www.broadinstitute.org/annotation/genome/botrytis_cinerea.2/Home.html) and URGI (http://urgi.versailles.inra.fr/index.php/urgi/Species/ Botrytis/Sequences-Databases). For amino acid sequence alignments the programs ClustalX 1.83 (ftp://ftp-igbmc. u-strasbg.fr/pub/ClustalX/) [48] and GeneDoc 2.5 (http://www.nrbsc.org/) [49] were used. Hydropathy plots were calculated with ProtScale (http://www.expasy. ch/cgi-bin/protscale.pl) [50] and drawn using Microsoft Excel. Prediction of signal sequences for secretion was performed using SignalP 3.0 (http://www.cbs.dtu.dk/ services/SignalP/) [51,52]. GRAVY values were computed with ProtParam (http://www.expasy.ch/tools/protparam.html) [50].

\section{Additional material}

Additional file 1: Hydrophobins and hydrophobin-like proteins encoded in the genomes of $B$. cinerea and $S$. sclerotiorum.

Additional file 2: Hydropathy plots of Bhl1 in comparison to Mpg1 (A) and Mhp1 (B).

Additional file 3: RT-PCR-based expression analysis of hydrophobin genes in mutant strains $\Delta b h p 1 / b h p 2, \Delta b h p 3 / b h p 2$ and $\Delta b h / 1$.

\section{Acknowledgements}

We are very grateful to Sabine Fillinger for generously providing us with fruiting bodies. We also thank Andreas Böhm for advice. This project was supported by the German Science Foundation (DFG: HA1486/5-1).

\section{Author details}

${ }^{1}$ Department of Biology, University of Kaiserslautern, Gottlieb-Daimler-Straße, 67663 Kaiserslautern, Germany. ${ }^{2}$ Department of Biology, University of Konstanz, Universitätsstraße 10, 78457 Konstanz, Germany.

\section{Authors' contributions}

AM performed the experiments, except for scanning electron microscopy which was performed by KWM. ML co-supervised the project. AM and $\mathrm{MH}$, who supervised the project, wrote the manuscript. All authors read and approved the final manuscript.

Received: 12 November 2010 Accepted: 13 January 2011

Published: 13 January 2011

\section{References}

1. Wessels JGH: Fungal hydrophobins: Proteins that function at an interface. Trends Plant Sci 1996, 1:9-15. 
2. Wösten HAB: Hydrophobins: multipurpose proteins. Annu Rev Microbio 2001, 55:625-646.

3. Kwan AHY, Winefield RD, Sunde M, Matthews JM, Haverkamp RG, Templeton MD, Mackay JP: Structural basis for rodlet assembly in fungal hydrophobins. Proc Natl Acad Sci USA 2006, 103:3621-3626.

4. Talbot NJ, Kershaw MJ, Wakley GE, De Vries OMH, Wessels JGH, Hamer JE: MPG1 Encodes a fungal hydrophobin involved in surface interactions during infection-related Development of Magnaporthe grisea. Plant Cell 1996, 8:985-999.

5. Beckerman JL, Ebbole DJ: MPG1, a gene encoding a fungal hydrophobin of Magnaporthe grisea, is involved in surface recognition. Mol PlantMicrobe Interact 1996, 9:450-456.

6. Kim S, Ahn IP, Rho HS, Lee YH: MHP1, a Magnaporthe grisea hydrophobin gene, is required for fungal development and plant colonization. Mol Microbiol 2005, 57:1224-1237.

7. Bowden CG, Smalley E, Guries RP, Hubbes M, Temple B, Horgen PA: Lack of association between cerato-ulmin production and virulence in Ophiostoma novo-ulmi. Mol Plant-Microbe Interact 1996, 9:556-564.

8. Temple B, Horgen PA, Bernier L, Hintz WE: Cerato-ulmin, a hydrophobin secreted by the causal agents of Dutch elm disease, is a parasitic fitness factor. Fungal Genet Biol 1997, 22:39-53.

9. Whiteford JR, Spanu PD: The hydrophobin HCf-1 of Cladosporium fulvum is required for efficient water-mediated dispersal of conidia. Fungal Genet Biol 2001, 32:159-168.

10. Doss RP, Potter SW, Chastagner GA, Christian JK: Adhesion of nongerminated Botrytis cinerea conidia to several substrata. Appl Environ Microbiol 1993, 59:1786-1791.

11. Doss RP, Potter SW, Soeldner AH, Christian JK, Fukunaga LE: Adhesion of germlings of Botrytis cinerea. Appl Environ Microbiol 1995, 61:260-265.

12. Doss RP: Composition and enzymatic activity of the extracellular matrix secreted by germlings of Botrytis cinerea. Appl Environ Microbiol 1999, 65:404-408.

13. Doehlemann $G$, Berndt $P$, Hahn M: Different signalling pathways involving a Galpha protein, CAMP and a MAP kinase control germination of Botrytis cinerea conidia. Mol Microbiol 2006, 59:821-835.

14. Shaw BD, Carroll GC, Hoch HC: Generality of the prerequisite of conidium attachment to a hydrophobic substratum as a signal for germination among Phyllosticta species. Mycologia 2006, 98:186-194.

15. Chaky J, Anderson K, Moss M, Vaillancourt L: Surface hydrophobicity and surface rigidity induce spore germination in Colletotrichum graminicola. Phytopathology 2001, 91:558-564.

16. Fuchs U, Czymmek KJ, Sweigard JA: Five hydrophobin genes in Fusarium verticillioides include two required for microconidial chain formation. Fungal Genet Biol 2004, 41:852-864.

17. Klimes A, Dobinson KF: A hydrophobin gene, VDH1, is involved in microsclerotial development and spore viability in the plant pathogen Verticillium dahliae. Fungal Genet Biol 2006, 43:283-294.

18. Talbot NJ, Ebbole DJ, Hamer JE: Identification and characterization of MPG1, a gene involved in pathogenicity from the rice blast fungus Magnaporthe grisea. Plant Cell 1993, 5:1575-1590.

19. Stringer MA, Dean RA, Sewall TC, Timberlake WE: Rodletless, a new Aspergillus developmental mutant induced by directed gene inactivation. Genes Dev 1991, 5:1161-1171.

20. Wösten HAB, Schuren FHJ, Wessels JGH: Interfacial self-assembly of a hydrophobin into an amphipathic protein membrane mediates fungal attachment to hydrophobic surfaces. EMBO J 1994, 13:5848-5854.

21. Thau N, Monod M, Crestani B, Rolland C, Tronchin G, Latgé JP, Paris S: Rodletless mutants of Aspergillus fumigatus. Infect Immun 1994, 62:4380-4388

22. Doss RP, Potter SW, Christian JK, Soeldner AH, Chastagner GA: The conidial surface of Botrytis cinerea and several other Botrytis species. Can J Bot 1997, 75:612-617.

23. Wösten HAB, Bohlmann R, Eckerskorn C, Lottspeich F, Bölker M, Kahmann R A novel class of small amphipathic peptides affect aerial hyphal growth and surface hydrophobicity in Ustilago maydis. EMBO J 1996, 15:4274-4281.

24. Teertstra WR, Deelstra HJ, Vranes M, Bohlmann R, Kahmann R, Kämper J, Wösten HAB: Repellents have functionally replaced hydrophobins in mediating attachment to a hydrophobic surface and in formation of hydrophobic aerial hyphae in Ustilago maydis. Microbiology 2006, 152:3607-3612.
25. Aimanianda V, Bayry J, Bozza S, Kniemeyer O, Perruccio K, Elluru SR, Clavaud C, Paris S, Brakhage AA, Kaveri SV, Romani L, Latgé JP: Surface hydrophobin prevents immune recognition of airborne fungal spores. Nature 2009, 460:1117-1121.

26. Jürgensen CW, Madsen AM: Exposure to the airborne mould Botrytis and its health effects. Ann Agric Environ Med 2009, 16:183-196.

27. Kazmierczak P, Kim DH, Turina M, Van Alfen NK: A hydrophobin of the chestnut blight fungus, Cryphonectria parasitica, is required for stromal pustule eruption. Eukaryot Cell 2005, 4:931-936.

28. Lacroix H, Whiteford JR, Spanu PD: Localization of Cladosporium fulvum hydrophobins reveals a role for HCf-6 in adhesion. FEMS Microbiol Lett 2008, 286:136-144

29. Lacroix H, Spanu PD: Silencing of six hydrophobins in Cladosporium fulvum: complexities of simultaneously targeting multiple genes. Appl Environ Microbiol 2009, 75:542-546.

30. Deising H, Nicholson RL, Haug M, Howard RJ, Mendgen K: Adhesion pad formation and the involvement of cutinase and esterases in the attachment of uredospores to the host cuticle. Plant Cell 1992, 4:1101-1111.

31. Cook RTA, Inman AJ, Billings C: Identification and classification of powdery mildew anamorphs using light and scanning electron microscopy and host range data. Mycol Res 1997, 101:975-1002.

32. Jackson LL, Dobbs L, Hildebrand A, Yokiel RA: Surface lipids of wheat stripe rust uredospores, Puccinia striiformis, compared to those of the host. Phytochemistry 1973, 12:2233-2237.

33. Clement JA, Porter R, Butt TM, Beckett A: The role of hydrophobicity in attachment of urediniospores and sporelings of Uromyces viciae-fabae. Mycol Res 1994, 98:1217-1228.

34. Newey LJ, Caten CE, Green JR: Rapid adhesion of Stagonospora nodorum spores to a hydrophobic surface requires pre-formed cell surface glycoproteins. Mycol Res 2007, 111:1255-1267.

35. Verstrepen KJ, Klis FM: Flocculation, adhesion and biofilm formation in yeasts. Mol Microbiol 2006, 60:5-15.

36. De Groot PWJ, Kraneveld EA, Yin QY, Dekker HL, Gross U, Crielaard W, de Koster CG, Bader O, Klis FM, Weig M: The cell wall of the human pathogen Candida glabrata: Differential incorporation of novel adhesinlike wall proteins. Eukaryot Cell 2008, 7:1951-1964.

37. Linder T, Gustafsson CM: Molecular phylogenetics of ascomycotal adhesins - A novel family of putative cell-surface adhesive proteins in fission yeasts. Fungal Genet Biol 2008, 45:485-497.

38. Hamada W, Reignault P, Bompeix G, Boccara M: Transformation of Botrytis cinerea with the hygromycin B resistance gene, hph. Curr Genet 1994, 26:251-255.

39. Malonek S, Rojas MC, Hedden P, Gaskin P, Hopkins P, Tudzynski B: The $\mathrm{NADPH}$-cytochrome $\mathrm{P} 450$ reductase gene from Gibberella fujikuroi is essential for gibberellin biosynthesis. J Biol Chem 2004, 279:25075-25084

40. Kück U, Hoff B: Application of the nourseothricin acetyltransferase gene (nat1) as dominant marker for the transformation of filamentous fungi. Fungal Genet Newsl 2006, 53:9-11.

41. Mattern IE, Punt PJ, Van den Hondel CAMJJ: A vector for Aspergillus transformation conferring phleomycin resistance. Fungal Genet Newsl 1988, 35:25-30.

42. Möller EM, Bahnweg G, Sandermann H, Geiger HH: A simple and efficient protocol for isolation of high molecular weight DNA from filamentous fungi, fruit bodies, and infected plant tissues. Nucl Acids Res 1992, 20:6115-6116.

43. Doehlemann G, Molitor F, Hahn M: Molecular and functional characterization of a fructose specific transporter from the gray mold fungus Botrytis cinerea. Fungal Genet Biol 2005, 42:601-610.

44. Schamber A, Leroch M, Diwo J, Mendgen K, Hahn M: The role of mitogenactivated protein (MAP) kinase signalling components and the Ste12 transcription factor in germination and pathogenicity of Botrytis cinerea. Mol Plant Pathol 2010, 11:105-119.

45. Reis H, Pfiffi S, Hahn M: Molecular and functional characterization of a secreted lipase from Botrytis cinerea. Mol Plant Pathol 2005, 6:257-267.

46. Malardier L, Daboussi MJ, Julien J, Roussel F, Scazzocchio C, Brygoo Y: Cloning of the nitrate reductase gene (niaD) of Aspergillus nidulans and its use for transformation of Fusarium oxysporum. Gene 1989, 78:147-156.

47. Schamber A, Leroch M, Diwo J, Mendgen K, Hahn M: The role of mitogenactivated protein (MAP) kinase signalling components and the Ste12 transcription factor in germination and pathogenicity of Botrytis cinerea. Mol Plant Pathol 2010, 11:105-119. 
48. Thompson JD, Gibson TJ, Plewniak F, Jeanmougin F, Higgins DG: The CLUSTAL_X windows interface: flexible strategies for multiple sequence alignment aided by quality analysis tools. Nucleic Acids Res 1997, 25:4876-4882.

49. Nicholas KB, Nicholas HB Jr, Deerfield DWII: GeneDoc: Analysis and visualization of genetic variation. EMBNet News 1997, 4:14.

50. Gasteiger E, Hoogland C, Gattiker A, Duvaud S, Wilkins MR, Appel RD, Bairoch A: Protein identification and analysis tools on the ExPASy server. In The Proteomics Protocols Handbook. Edited by: Walker JM. Humana Press; 2005:571-607.

51. Nielsen H, Engelbrecht J, Brunak S, von Heijne G: Identification of prokaryotic and eukaryotic signal peptides and prediction of their cleavage sites. Protein Eng 1997, 10:1-6.

52. Bendtsen JD, Nielsen H, von Heijne G, Brunak S: Improved prediction of signal peptides: SignalP 3.0. J Mol Biol 2004, 340:783-795.

53. Kyte J, Doolittle RF: A simple method for displaying the hydropathic character of a protein. J Mol Biol 1982, 157:105-132.

doi:10.1186/1471-2180-11-10

Cite this article as: Mosbach et al: Lack of evidence for a role of hydrophobins in conferring surface hydrophobicity to conidia and hyphae of Botrytis cinerea. BMC Microbiology 2011 11:10.

\section{Submit your next manuscript to BioMed Central} and take full advantage of:

- Convenient online submission

- Thorough peer review

- No space constraints or color figure charges

- Immediate publication on acceptance

- Inclusion in PubMed, CAS, Scopus and Google Scholar

- Research which is freely available for redistribution

Submit your manuscript at www.biomedcentral.com/submit
C Biomed Central 